\title{
Insulin Resistance as a Membrane Microdomain Disorder
}

\author{
Jin-ichi INOKUCHI \\ Division of Glycopathology and CREST, Japan Science and Technology Agency, Institute of Molecular Biomembrane \\ and Glycobiology, Tohoku Pharmaceutical University, 4-4-1 Komatsushima, Aoba-ku, Sendai 981-8558, Japan
}

(Received January 5, 2007)

\begin{abstract}
Membrane microdomains (lipid rafts) are now recognized as critical for proper compartmentalization of insulin signaling, but their role in the pathogenesis of insulin resistance has not been investigated. Detergent-resistant membrane microdomains (DRMs), isolated in the low density fractions, are highly enriched in cholesterol, glycosphingolipids and various signaling molecules. TNF $\alpha$ induces insulin resistance in type 2 diabetes, but its mechanism of action is not fully understood. We have found a selective increase in the acidic glycosphingolipid ganglioside GM3 in 3T3-L1 adipocytes treated with $\mathrm{TNF} \alpha$, suggesting a specific function for GM3. We were able to extend these in vitro observations to living animals using obese Zucker $f a / f a$ rats and $o b / o b$ mice, in which the GM3 synthase mRNA levels in the white adipose tissues are significantly higher than in their lean controls. In the DRMs from TNF $\alpha$-treated 3T3-L1 adipocytes, GM3 levels were doubled, compared to results in normal adipocytes. Additionally, insulin receptor (IR) accumulations in the DRMs were diminished, while caveolin and flotillin levels were unchanged. GM3 depletion was able to counteract the $\mathrm{TNF} \alpha$-induced inhibition of IR accumulation into DRMs. Together, these findings provide compelling evidence that in insulin resistance the insulin metabolic signaling defect can be attributed to a loss of IRs in the microdomains due to an accumulation of GM3.
\end{abstract}

Key words_ _ insulin receptor; insulin resistance; ganglioside GM3; lipid rafts; detergent-resistant microdomain (DRM)

\section{INTRODUCTION}

Insulin resistance, defined as the decreased ability of cells or tissues to respond to physiological levels of insulin, is thought to be the primary defect in the pathophysiology of type 2 diabetes. ${ }^{1)}$ Numerous studies have implicated TNF $\alpha$ as having a role in insulin resistance, both in cultured adipocyte and wholeanimal models. ${ }^{2-4)}$ Several lines of evidence suggest that tumor necrosis factor (TNF) $\alpha$ represents a key mediator of obesity-linked insulin resistance. First, overexpression of $\mathrm{TNF} \alpha$ in adipose tissue and insulin resistance were commonly observed in different rodent models of obesity ${ }^{2,3}$ as well as in obese humans. ${ }^{4)}$ Second, neutralization of $\mathrm{TNF} \alpha$ with a soluble $\mathrm{TNF} \alpha$ receptor-immunoglobulin $\mathrm{G}$ chimeric protein was found to improve insulin receptor signaling and insulin sensitivity in obese and insulinresistant rats. ${ }^{2)}$ Moreover, obese mice with targeted disruption of the genes encoding either TNF $\alpha$ or its two receptors lacked insulin resistance. ${ }^{4)}$ Third, on a cellular level, $\mathrm{TNF} \alpha$ is a potent inhibitor of insulin

e-mail: jin@tohoku-pharm.ac.jp

本総説は, 日本薬学会第126年会シンポジウムS10で発

表したものを中心に記述したものである. signaling. Chronic treatment of 3T3-L1 adipocytes with $\mathrm{TNF} \alpha$ inhibits glucose uptake and interferes with signaling through the insulin receptor to downstream of substrates, such as insulin receptor substrate-1 (IRS-1), suggesting a defect at or near the tyrosine kinase activity. ${ }^{5)}$ Although there is now substantial evidence linking $\mathrm{TNF} \alpha$ to the presentation of insulin resistance in humans, animals, and in vitro systems as described above, the molecular mechanisms mediating the crosstalk between $\mathrm{TNF} \alpha$ and the insulin signaling cascade remain incompletely understood.

A key question is whether TNF $\alpha$ acts directly or indirectly to suppress insulin function. In adipocytes cultured in relatively low concentrations of $\mathrm{TNF} \alpha$ (which do not cause a generalized suppression of gene expression), interference with insulin action occurs. This effect requires prolonged treatment (at least 72 h), unlike many acute responses to this cytokine. This protracted effect suggests that $\mathrm{TNF} \alpha$ induces the synthesis of an inhibitor that is the actual effector.

One clue as to the mechanism of this hormone's unique actions may lie in the compartmentalization of the signaling molecules themselves. Cellular membranes contain sub-domains called detergent resistant microdomains (DRMs), because they are detergent- 
insoluble and highly enriched in cholesterol and glycosphingolipids (GSLs), but lacking in phospholipids. ${ }^{67)}$ Within the past decade, data have emerged from many laboratories implicating these lipid microdomains as critical for proper compartmentalization of insulin signaling in adipocytes (reviewed in Refs. 8) and 9))

Gangliosides, a family of sialic acid-containing GSLs, are an important component of DRMs. In adipose tissues from various species, including human and mouse, GM3 is the most abundant ganglioside. ${ }^{10)}$ Recently, we reported that in mouse 3T3-L1 adipocytes insulin resistance induced by $\mathrm{TNF} \alpha$ was accompanied by increased GM3 expression. We were able to extend these in vitro observations to living animals using obese Zucker $f a / f a$ rats and $o b / o b$ mice, in which the GM3 synthase mRNA levels in the white adipose tissues are significantly higher than in their lean controls. Moreover, we examined the effect of $\mathrm{TNF} \alpha$ on the composition and function of DRMs in adipocytes and demonstrated that increased GM3 levels result in the elimination of IRs from the DRMs while caveolin and flotillin remain in the DRMs, leading to the inhibition of insulin's metabolic signaling. ${ }^{11)}$ Thus, we present a new pathological feature of insulin resistance in adipocytes induced by $\mathrm{TNF} \alpha$.

\section{EFFECTS OF TNF $\alpha$ AND D-PDMP ON INSULIN SIGNALING THROUGH IR TO IRS-1}

We first examined the effects of low TNF $\alpha$ concentrations on the levels of the IR and IRS-1 proteins, since high concentrations of $\mathrm{TNF} \alpha$ induce dedifferentiation of adipocytes and reduce gene expression on components of the IR signal transduction pathway, such as IRS-1 and glucose transporter 4 (GLUT4) genes. ${ }^{3,5,12)}$ Fully differentiated 3T3-L1 adipocytes were treated with $0.1 \mathrm{nM} \mathrm{TNF} \alpha$ for $96 \mathrm{~h}$ as described previously. ${ }^{13)} \mathrm{TNF} \alpha$ induced a moderate decrease of insulin stimulated phosphorylation of the IR and a more pronounced inhibition of insulin-promoted phosphorylation of IRS-1 without affecting expression of either the IR or IRS-1 (Fig. 1(A)). Marked accumulation of GM3 - occurred with $\mathrm{TNF} \alpha$ treatment (Fig. 1(B)). One approach to depleting cellular gangliosides is the use of an inhibitor of glucosylceramide synthase, D-PDMP, a well-known tool for studying various functional roles of endogenous glycosphingolipids including gangliosides. ${ }^{14,15)} \mathrm{D}$ PDMP lowered GM3 content in 3T3-L1 adipocytes treated without or with $\mathrm{TNF} \alpha$ (Fig. 1(B)), with a concomitant increase of tyrosine phosphorylation of IRS-1 in response to insulin stimulation (Fig. 1(A)) . The binding affinity of insulin to adipocytes treated with $20 \mu \mathrm{M}$ D-PDMP for $96 \mathrm{~h}$ was similar to that of the non-treated control cells, indicating that GM3 depletion by D-PDMP treatment does not affect insulin binding to its receptor and that the D-PDMP treatment affects the insulin signaling pathway through IR to IRS-1.

\section{ENHANCED EXPRESSION OF GM3 SYNTHASE MRNA IN ADIPOSE TISSUES FROM TYPICAL RODENT MODELS OF INSULIN RESISTANCE}

It was shown that adipose tissues of the obese-diabetic $d b / d b, o b / o b, \mathrm{KK}-\mathrm{A}^{\mathrm{y}}$ mice, and the Zucker $f a /$ $f a$ rats produced significant levels of TNF $\alpha{ }^{3)}$ Much less expression was seen in fat obtained from the lean control animals. Interestingly, those obese-diabetic animals did not show evidence of altered expression of other cytokines, such as TNF $\beta$, IL- 1 or IFN $\gamma .{ }^{3,16)}$ Thus, we were interested in measuring the expression of GM3 synthase mRNA in the epididymal fat of Zucker $f a / f a$ rats and $o b / o b$ mice. Northern blot analysis of GM3 synthase mRNA contents in the adipose tissues from these two typical models of insulin resistance exhibited significant high levels compared to their lean counterparts (Fig. 2).

\section{IR IS A COMPONENT OF THE DRMS AND IS SELECTIVELY ELIMINATED FROM THE DRMS DURING A STATE OF INSULIN RESISTANCE INDUCED BY TNF $\alpha$}

Studies of the presence of IRs in DRMs/caveolae have provided conflicting data. ${ }^{17-19)} \mathrm{We}$ evaluated

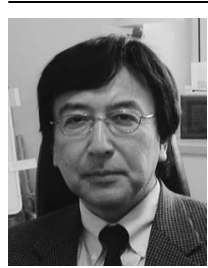

Jin-ichi Inokuchi

He received a Ph.D. degree in 1984 from the Department of Biochemistry, Faculty of Pharmaceutical Sciences, Fukuoka University. In 1985 he moved to the Mental Health Research Institute, University of Michigan, and, in 1992, became the head of the Glycolipid Section, Tokyo Research Institute, SEIKAGAKU CORPORATION. In 1998 he moved to Hokkaido University as an associate professor. In 2006, he became a professor at the Institute of Molecular Biomembranes and Glycobiology, Tohoku Pharmaceutical University. He is a principal investigator of CREST, Japan Science and Technology Agency. 
A

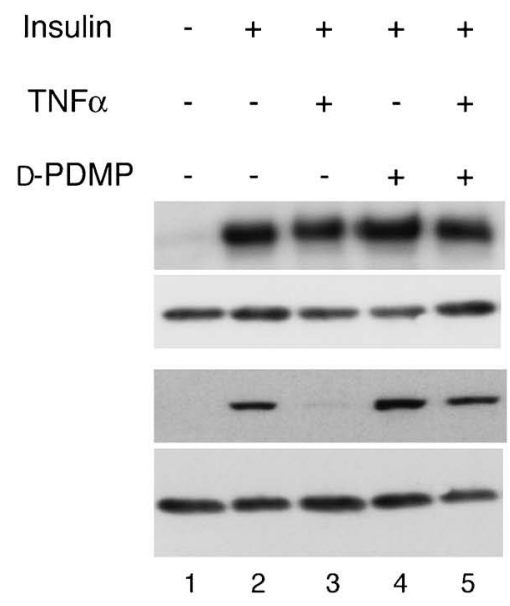

$\mathrm{B}$

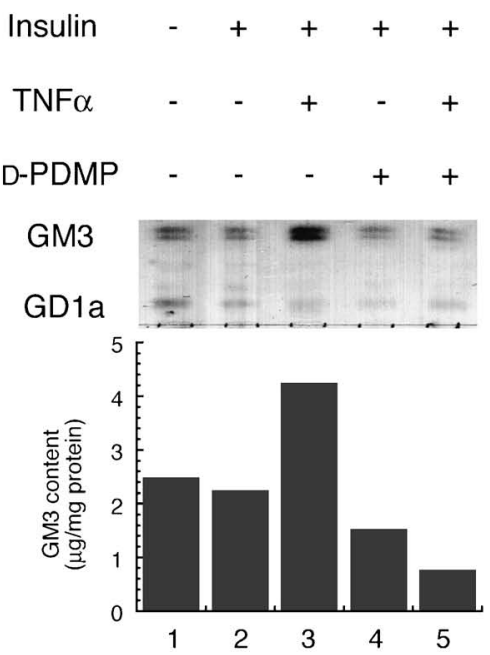

Fig. 1. TNF $\alpha$ Increases the Expression of GM3 and Prevention of GM3 Synthesis Reverses TNF $\alpha$ Induced Suppression Insulin Signaling in Adipocytes ${ }^{21}$

(A) 3T3-L1 adipocytes were cultured in maintenance medium without-(lanes 1, 2 and 4) or with (lanes 3 and 5) $0.1 \mathrm{nM}$ TNF $\alpha$ for $96 \mathrm{~h}$ and in order to deplete GM3, $20 \mu \mathrm{M}$ D-PDMP was also included (lanes 4 and 5). Before insulin stimulation ( $100 \mathrm{nM}$ for $3 \mathrm{~min}$ ), cells were starved in serum-free media containing $0.5 \%$ bovine serum albumin in the absence or presence of TNF $\alpha$ and D-PDMP as above for $8 \mathrm{~h}$. Proteins in cell lysates were immunoprecipitated with antiserum to IR and IRS-1, fractionated by SDS-PAGE, and transferred to Immobilon-P. Western blot was then proved with anti-phosphotyrosine monoclonal antibody, stripped and reproved with antiserum to IR and IRS-1, (B) 3T3-L1 adipocytes were incubated in the absence or presence of TNF $\alpha$ and D-PDMP as in (A) and the ganglioside fraction was visualized by resorcinol staining on HPTLC. Reproducible results were obtained with four independent experiments.

\section{Zucker fa/fa rats}

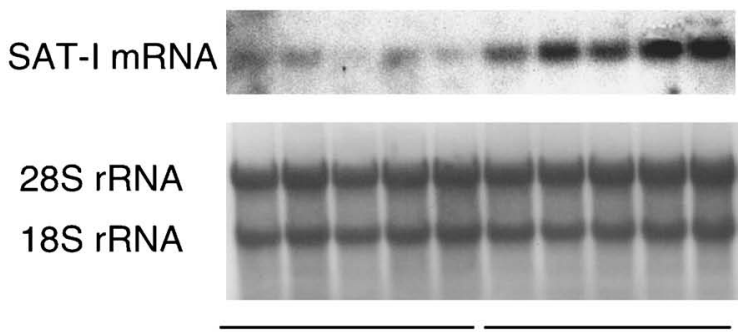

$\mathrm{fa} / \mathrm{-}$

fa/fa $o b / o b$ mice

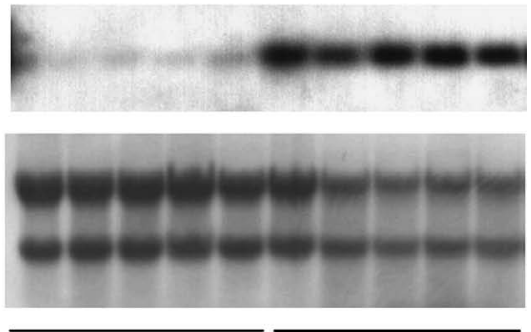

$o b /-$

$a b / o b$

Fig. 2. Increased GM3 Synthase mRNA in Adipose Tissue of Typical Rodent Models of Insulin Resistance ${ }^{21)}$

Northern blot analysis of GM3 synthase mRNA was performed using total mRNA from adipose tissues of Zucker $f a / f a$ rats and $o b / o b$ mice, and their lean counterparts.

the localization of IRs in a flotation assay following extraction with increasing concentrations of Triton $\mathrm{X}-100$, or under hypertonic alkaline conditions (500 mM sodium carbonate) (Fig. 3 ). In the carbonate buffer, IRs from normal 3T3-L1 cells were found exclusively in the low density, insoluble fractions 4 and 5 , which are known to carry DRMs, whereas a small portion of the IRs in TNF $\alpha$-treated cells shifted to fractions 6-8. On the other hand, there was no accumulation in the DRMs in cells, untreated or treated with TNF $\alpha$ when examined using an extraction buffer containing $1 \%$ (data not shown) or $0.1 \%$ Triton
$\mathrm{X}-100$, concurring with a previous report using high levels of detergent. ${ }^{17)}$ However, when the flotation assay was performed using buffer with lower concentrations of Triton X-100 $(0.08 \%$ or $0.05 \%)$, the DRMs were able to hold the IRs, although in the TNF $\alpha$ treated cells the IRs tended to shift to higher density fractions. Next, using membranes extracted with the $0.08 \%$ Triton X-100 buffer, we analyzed the distribution of GM3 and cholesterol, and of proteins normally associated with DRMs (e.g., caveolin, flotillin, fyn), in each fraction of the sucrose density gradient (Fig. 4). GM3 was preferentially localized at the 


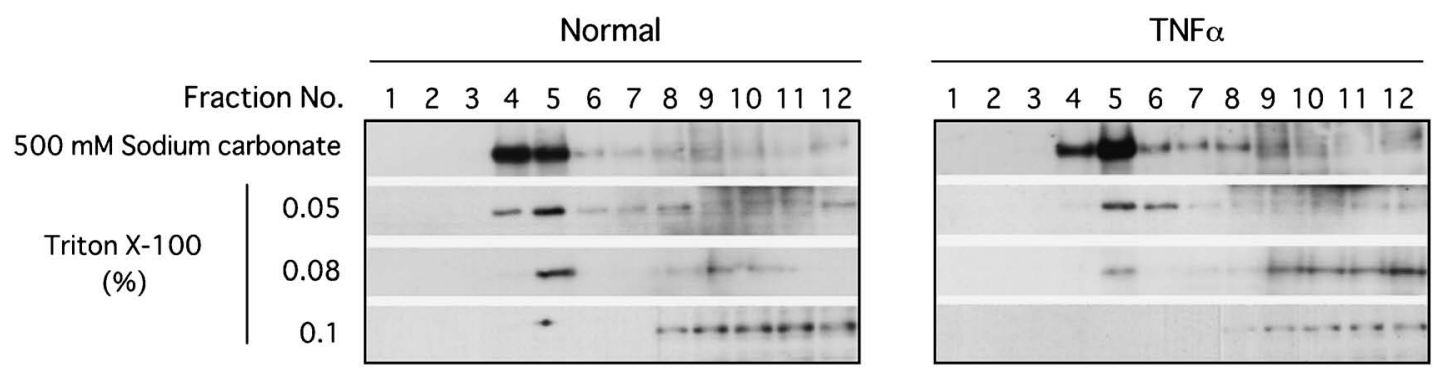

Fig. 3. IR can Localize to DRMs in Normal Adipocytes but Tends to Shift to High Density Fractions upon TNF $\alpha$ Treatment ${ }^{11)}$

$\mathrm{TNF} \alpha$ treated $(96 \mathrm{~h})$ or untreated adipocytes were homogenized with $500 \mathrm{mM}$ sodium carbonate non-detergent buffer, or lysed with buffer containing detergent $(0.05,0.08$, or $0.1 \%$ Triton $\mathrm{X}-100)$. Samples were then subjected to a sucrose density gradient flotation assay. The gradient fractions from low (1) to high (12) density were subjected to SDS-PAGE and immunoblotted with an anti-IR $\beta$ antibody.

A

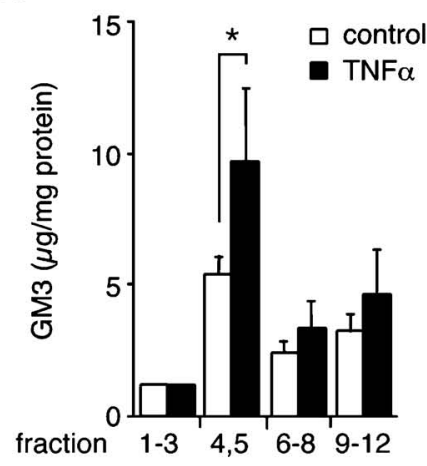

B

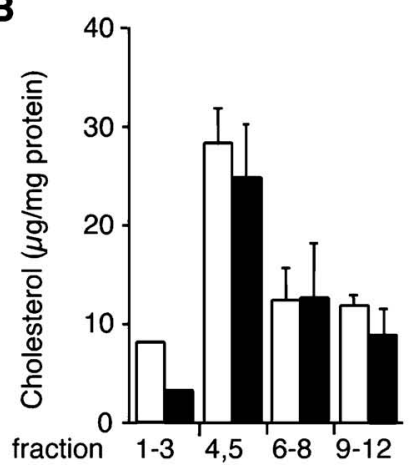

C

IB: $\quad$ TNF $\alpha$
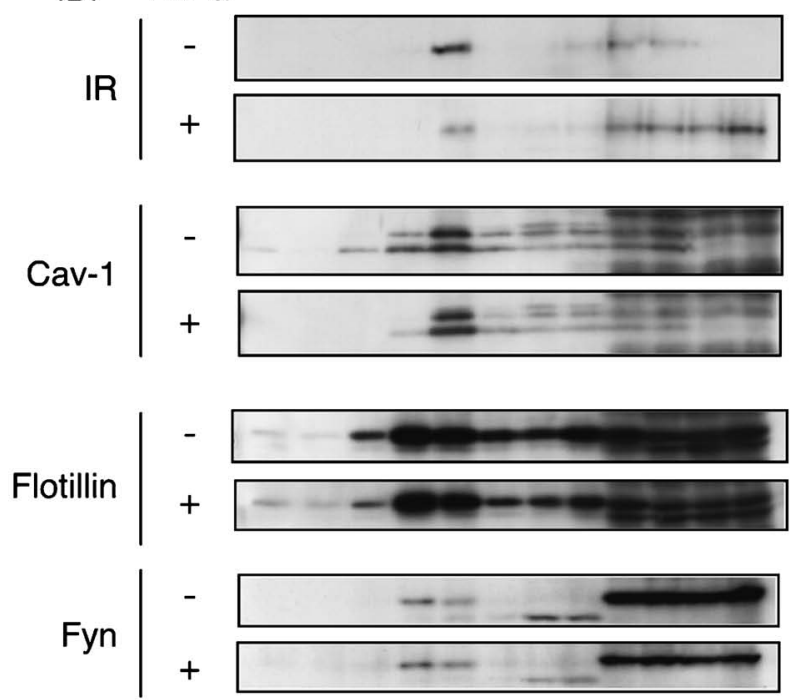

fraction: $\begin{array}{llllllllll}1 & 2 & 3 & 4 & 5 & 6 & 7 & 8 & 9 & 101112\end{array}$

Fig. 4. Accumulation of GM3 in the DRMs and Selective Dissociation of IRs from DRMs in a State of Insulin Resistance ${ }^{11}$

Adipocytes, untreated (open bars) or treated with $100 \mathrm{pM} \mathrm{TNF} \alpha$ for $96 \mathrm{~h}$ (solid bars), were lysed with buffer containing $0.08 \%$ Triton X-100 and subjected to a sucrose density gradient flotation assay. (A) GM3 levels in the sucrose gradient fractions were examined by HPTLC analysis. (B) Cholesterol levels in the sucrose gradient fractions were measured by a commercial assay. (C) The samples were subjected to SDS-PAGE and immunoblotted with antibodies against IR $\beta$, caveolin1, flotillin, or fyn. Data in (A) and (B) are shown as means \pm S.D. $(n=3) .{ }^{*} p<0.05$.

DRMs in both normal and TNF $\alpha$-treated 3T3-L1 adipocytes. Remarkably, though, the accumulation of GM3 observed in the DRMs was 2-fold higher in the TNF $\alpha$-treated cells (Fig. 4(A)). There were no distinct differences in the expression levels or distribution of cholesterol (Fig. 4(B)), caveolin, flotillin, or fyn (Fig. 4(C)). Taken together, these results clearly demonstrate the selective elimination of IRs from the DRMs and the accumulation of GM3 in adipocytes under a chronic state of $\mathrm{TNF} \alpha$-induced insulin resistance.

\section{GSL DEPLETION ATTENUATES THE TNF $\alpha$-IN- DUCED INHIBITION OF BOTH INSULIN- STIMULATED IR INTERNALIZATION AND DISSOCIATION OF IR FROM DRMS}

To investigate whether the inhibition of insulindependent IR internalization and the dissociation of 
IR from the microdomains in TNF $\alpha$-treated cells were due to increases in GM3, we employed an inhibitor of glucosylceramide synthase, D-threo-1-phenyl-2-decanoylamino-3-morpholino-1-propanol (D-PDMP). After GM3 depletion by D-PDMP, the suppression of IR internalization was indeed partially recovered. ${ }^{11)}$ Additionally, the dissociation of IRs from the DRMs was effectively blocked (Fig. 5). There was no obvious change in the accumulation of IR in the DRMs after insulin stimulation. These results indicate direct involvement of GM3 in the chronic state of insulin resistance in adipocytes.

\section{DISCUSSION}

Caveolae are a subset of membrane microdomains particularly abundant in adipocytes. Critical dependence of the insulin metabolic signal transduction on caveolae/microdomains in adipocytes has been demonstrated. Disruption of microdomains by cholesterol extraction with $\beta$-cyclodextrin resulted in progressive inhibition of tyrosine phosphorylation of IRS-1 and activation of glucose transport in response to insulin although autophosphorylation of IR and activation of MAP kinase were not impaired. ${ }^{20)}$ There were similarities between these cell culture results and the findings in many cases of clinical insulin resistance, ${ }^{1)}$ thereby suggesting a potential role for microdomains in the pathogenesis of this disorder. Gangliosides are also known as structurally and functionally important components in microdomains, however, there was no report on their role $(\mathrm{s})$ in microdomains in adipocytes.
We present evidence that the transformation to insulin resistant state induced in adipocytes by $\mathrm{TNF} \alpha$ may depend on increased ganglioside GM3 biosynthesis following upregulated GM3 synthase gene expression.

Additionally, GM3 may function as an inhibitor of insulin signaling during chronic exposure to $\mathrm{TNF} \alpha .{ }^{21}$ ) These findings are further supported by the report that mice lacking GM3 synthase exhibit enhanced insulin signaling. ${ }^{22)}$ Since GSLs, including GM3, are important components of DRMs/caveolae, we have pursued the possibility that increased GM3 levels in DRMs confer insulin resistance upon $\mathrm{TNF} \alpha$-treated 3T3-L1 adipocytes.

A few recent studies ${ }^{23,24)}$ indicate that typical cholesterol-dependent microdomains termed "lipid raft" having a GPI anchor, assumed to have a diameter of $10-20 \mathrm{~nm}$, may be too small to be involved in signal transduction, in contrast to major microdomains having sufficient size and organization of molecules. If "lipid raft" is defined by (i) resistance to $1 \%$ Triton X-100; (ii) cholesteroldependence; and (iii) small size (10-20 nm diameter or less), then the majority of ganglioside microdomains as described in this study are "nonlipid raft" because their size is presumed to be much larger, in analogy to glycolipid-enriched microdomains.

As summarized in Table 1, evidence suggesting that caveolae and caveolins play a major role in insulin signaling initially came from experiments using rat adipocytes, in which gold-labeled insulin was en-

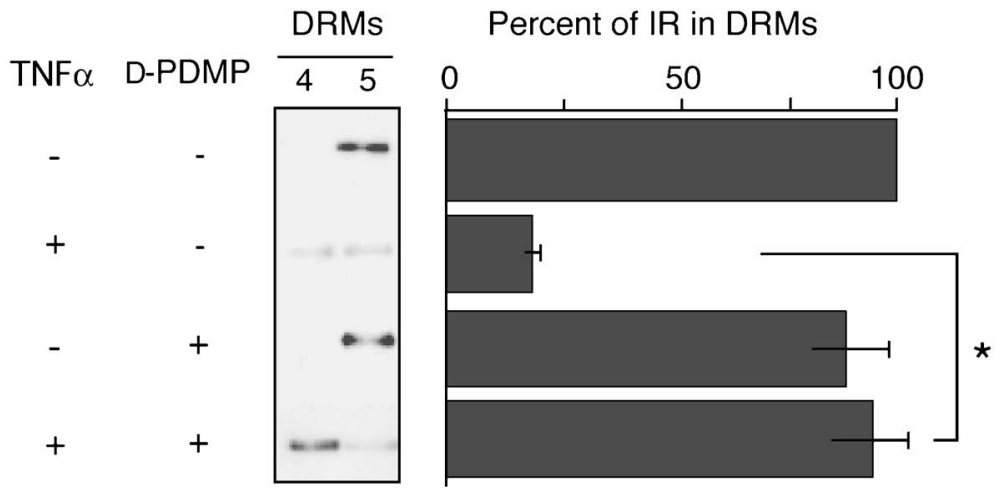

IB: anti-IR

Fig. 5. GM3-depletion Attenuates $\mathrm{TNF} \alpha$-induced Inhibition of Elimination of IR from the DRMs ${ }^{11)}$

3T3-L1 cells were cultured in maintenance medium with or without TNF $\alpha$ for $96 \mathrm{~h}$ in the presence or absence of $20 \mathrm{mM}$ D-PDMP. The cells were lysed with buffer containing $0.08 \%$ Triton X-100, and the lysates subjected to a sucrose density gradient flotation assay as in Fig. 3. Data shown are means \pm S.D. $(n=3)$. ${ }^{*} p$ $<0.05$. 
docytosed by a mechanism involving clathrin-independent, uncoated invaginations. ${ }^{25)}$ Immunogold electron $^{17)}$ and immunofluorescence microscopy ${ }^{18)}$ further demonstrated that IRs are highly concentrated in caveolae. Additionally, Couet et al., demonstrated the presence of a caveolin binding motif $(\phi \mathrm{X} \phi \mathrm{XXXX} \phi$ : where $\phi$ is aromatic amino acid) in the $\beta$-subunit of IRs that could bind to the scaffold domain of caveolin. ${ }^{26}$ ) Moreover, mutation of this motif resulted in the inhibition of insulin signaling. ${ }^{27)}$ Recently, Lisanti's laboratory reported that caveolin1-null mice developed insulin resistance when placed on a high fat diet. ${ }^{9)}$ Interestingly, insulin signaling, as measured by IR phosphorylation and its downstream targets, was selectively decreased in the adipocytes of these animals while signaling in both muscle and liver cells was normal. ${ }^{9)}$ This signaling defect was attributed to a $90 \%$ decrease in IR protein content in the adipocytes, with no changes in mRNA levels, indicating that caveolin-1 serves to stabilize the IR protein. ${ }^{9,28)}$ These studies clearly indicate the critical importance of the interaction between caveolin and IR in executing successful insulin signaling in adipocytes (Table 1).

Saltiel and colleagues found that insulin stimulation of 3T3-L1 adipocytes was associated with tyrosine phosphorylation of caveolin-1. ${ }^{29)}$ However, since only trace levels of IR were recovered in the caveolae microdomains in assays with a buffer of $1 \%$ Triton

Table 1. Localization of Insulin Receptor in Caveolae Microdomains is Essential for Insulin's Metabolic Signaling

1. Direct Binding of IR and Caveolin-1

IR has caveolin binding domain ${ }^{26)}$

Coimmunoprecipitation of IR and caveolin ${ }^{27)}$

2. Colocalization of IR and Caveolin-1

IR and caveolin in light-density fractions by sucrose density flotation assay ${ }^{11,34)}$

Fluorescence microscope ${ }^{17)}$

Electron microscope ${ }^{35)}$

3. Insulin Signaling via Caveolae

Stimulation of caveolin-1 tyrosine phosphorylation by insulin ${ }^{18,29)}$

Caveolin deficient mice show insulin resistance due to accelerated degradation of IR in adipose tissue ${ }^{9,36)}$

Cholesterol depletion disrupts caveolae and metabolic signaling of insulin ${ }^{20,37)}$

Increased GM3 eliminates IR from DRMs and inhibits IR-IRS-1 signaling ${ }^{11,21)}$
$\mathrm{X}-100$, they speculated on the presence of intermediate molecule(s) bridging IR and caveolin. ${ }^{19)}$ Gustavsson et al., also observed the dissociation of IRs from caveolin-containing DRMs after treatments of 0.3 and $0.1 \%$ Triton X-100. ${ }^{17)}$ It has been reported that comparison of protein and lipid contents of DRMs prepared with a variety of detergents exhibited the considerable differences in their ability to selectively solubilize membrane proteins and to enrich sphingolipids and cholesterol over glycerophospholipids, and Triton was the most reliable detergent. ${ }^{30)}$ Therefore, we performed a flotation assay with a wide range of Triton X-100 concentrations to identify the protein of interest which might weakly associate with DRMs (Figs. 3 and 4). In an assay system containing less than $0.08 \%$ Triton X-100, we were able to show that in normal adipocytes IRs can localize to DRMs. However, in the presence of TNF $\alpha$, IR was selectively eliminated from the DRMs while caveolin-1 remained (Fig. 4(C)). Thus, by employing low detergent concentrations we were able to demonstrate, for the first time, the presence of IR in DRMs. We currently believe that elimination of IR from the DRMs by TNF $\alpha$ treatment is due to an excessive accumulation of GM3 in these microdomains, especially since preventing GM3 biosynthesis using D-PDMP attenuated the elimination of IR from the DRMs (Fig. 5(B)). Reportedly, the localization in the DRMs of several proteins (including receptor protein tyrosine kinases) can be affected by changes in the expression levels of GSLs. For example, overexpression of the ganglioside GM1 in Swiss 3T3 cells results in the dispersion of $\beta$ type platelet-derived growth factor receptor from the DRMs. ${ }^{31)}$ Similarly, the genetically enhanced accumulation of endogenous GM3 in keratinocytes caused the dissociation of caveolin-1 from the DRMs, thereby changing the signaling of the epidermal growth factor receptor. ${ }^{32)}$ In $\mathrm{HuH} 7$ hepatoma cells, which lack caveolin, IRs associate with DRMs in response to insulin stimulation, but crosslinking of GM2 by its antibody results in a loss of this association. ${ }^{33)}$ Such results support the likelihood that localization of IRs to the DRMs is affected by the presence of not only caveolin but also GSLs, especially gangliosides. Additionally, tyrosine phosphorylation of IRS-1 in response to insulin was selectively impaired without affecting the activation of IR and MAPK. ${ }^{21)}$ The observed impairment of IR-IRS-1 signaling by TNF $\alpha$ may be attributed to the elimination 

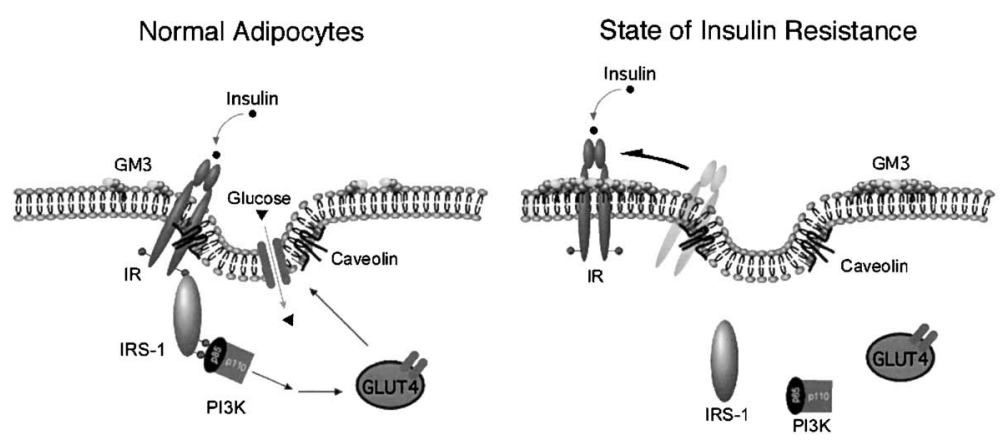

Fig. 6. Proposed Model of Caveolae Microdomains in the State of Insulin Resistance in Adipocytes

of IR from microdomains due to the excess accumulation of GM3 (Fig. 4(A)). Although the localization of IRs to DRMs may be maintained by the association with caveolin-1 as mentioned above, the excess accumulation of GM3 in the DRMs may weaken the IRcaveolin interaction. Indeed, IR but not caveolin-1 was co-immunoprecipitated with anti-GM3 antibody (unpublished observation).

\section{CONCLUSIONS}

The current view of microdomains in the state of insulin resistance is depicted in Fig. 6. We propose a working hypothesis "Life style-related diseases such as type 2 diabetes are membrane microdomain disorders caused by aberrant expression of glycosphingolipids". Further work is in progress to elucidate the mechanisms for the interactions of the ganglioside GM3, IR and caveolin in the microdomains.

Acknowledgements The author would like to thank all past collaborators who were involved in the studies described in this review article.

\section{REFERENCES}

1) Virkamaki A., Ueki K., Kahn C. R., J. Clin. Invest., 103, 931-943 (1999).

2) Hotamisligil G. S., Arner P., Caro J. F., Atkinson R. L., Spiegelman B. M., J. Clin. Invest., 95, 2409-2415 (1995).

3) Hotamisligil G. S., Shargill N. S., Spiegelman B. M., Science, 259, 87-91 (1993).

4) Uysal K. T., Wiesbrock S. M., Marino M. W., Hotamisligil G. S., Nature, 389, 610-614 (1997) .

5) Hotamisligil G. S., Murray D. L., Choy L. N., Spiegelman B. M., Proc. Natl. Acad. Sci. U.S.A., 91, 4854-4858 (1994).
6) Hakomori S. I., Glycoconj. J., 17, 143-151 (2000).

7) Simons K., Toomre D., Nat. Rev. Mol. Cell Biol., 1, 31-39 (2000).

8) Bickel P. E., Am. J. Physiol. Endocrinol. Metab., 282, E1-E10 (2002).

9) Cohen A. W., Razani B., Wang X. B., Combs T. P., Williams T. M., Scherer P. E., Lisanti M. P., Am. J. Physiol. Cell Physiol., 285, C222-235 (2003).

10) Ohashi M., Lipids, 14, 52-57 (1979).

11) Kabayama K., Sato T., Kitamura F., Uemura S., Kang B. W., Igarashi Y., Inokuchi J., Glycobiology, 15, 21-29 Epub 2004 Aug 2011 (2005).

12) Stephens J. M., Lee J., Pilch P. F., J. Biol. Chem., 272, 971-976 (1997).

13) Guo D., Donner D. B., J. Biol. Chem., 271, 615-618 (1996).

14) Inokuchi J., Momosaki K., Shimeno H., Nagamatsu A., Radin N. S., J. Cell Physiol., 141, 573-583 (1989).

15) Radin N. S., Shayman J. A., Inokuchi J., Adv. Lipid Res., 26, 183-213 (1993).

16) Hotamisligil G. S., Spiegelman B. M., Diabetes, 43, 1271-1278 (1994).

17) Gustavsson J., Parpal S., Karlsson M., Ramsing C., Thorn H., Borg M., Lindroth M., Peterson K. H., Magnusson K. E., Stralfors P., Faseb. J., 13, 1961-1971 (1999) .

18) Kimura A., Mora S., Shigematsu S., Pessin J. E., Saltiel A. R., J. Biol. Chem., 277, 3015330158 (2002).

19) Mastick C. C., Saltiel A. R., J. Biol. Chem., 272, 20706-20714 (1997).

20) Parpal S., Karlsson M., Thorn H., Stralfors P., J. Biol. Chem., 276, 9670-9678 (2001). 
21) Tagami S., Inokuchi Ji-I., Kabayama K., Yoshimura H., Kitamura F., Uemura S., Ogawa C., Ishii A., Saito M., Ohtsuka Y., Sakaue S., Igarashi Y., J. Biol. Chem., 277, 30853092, Epub 2001 Nov 3013 (2002).

22) Yamashita T., Hashiramoto A., Haluzik M., Mizukami H., Beck S., Norton A., Kono M., Tsuji S., Daniotti J. L., Werth N., Sandhoff R., Sandhoff K., Proia R. L., Proc. Natl. Acad. Sci. U.S.A., 100, 3445-3449, Epub 2003 Mar 3410 (2003).

23) Munro S., Cell, 115, 377-388 (2003).

24) Glebov O. O., Nichols B. J., Nat. Cell Biol., 6, 238-243, Epub 2004 Feb 2008 (2004).

25) Goldberg R. I., Smith R. M., Jarett L., J. Cell. Physiol., 133, 203-212 (1987),

26) Couet J., Li S., Okamoto T., Ikezu T., Lisanti M. P., J. Biol. Chem., 272, 6525-6533 (1997).

27) Nystrom F. H., Chen H., Cong L. N., Li Y., Quon M. J., Mol. Endocrinol., 13, 2013-2024 (1999)

28) Cohen A. W., Combs T. P., Scherer P. E., Lisanti M. P., Am. J. Physiol. Endocrinol. Metab., 285, E1151-1160 (2003).

29) Mastick C. C., Brady M. J., Saltiel A. R., J. Cell Biol., 129, 1523-1531 (1995).
30) Schuck S., Honsho M., Ekroos K., Shevchenko A., Simons K., Proc. Natl. Acad. Sci. U.S.A., 100, 5795-5800 (2003).

31) Mitsuda T., Furukawa K., Fukumoto S., Miyazaki H., Urano T., J. Biol. Chem., 277, 11239-11246 (2002).

32) Wang X. Q., Sun P., Paller A. S., J. Biol. Chem., 277, 47028-47034 (2002).

33) Vainio S., Heino S., Mansson J. E., Fredman P., Kuismanen E., Vaarala O., Ikonen E., EMBO Rep., 3, 95-100 (2002).

34) Yamamoto M., Toya Y., Schwencke C., Lisanti M. P., Myers Jr. M. G., Ishikawa Y., J. Biol. Chem., 273, 26962-26968 (1998) .

35) Karlsson M., Thorn H., Danielsson A., Stenkula K. G., Ost A., Gustavsson J., Nystrom F. H., Stralfors P., Eur. J. Biochem., 271, 2471-2479 (2004).

36) Capozza F., Cohen A. W., Cheung M. W., Sotgia F., Schubert W., Battista M., Lee H., Frank P. G., Lisanti M. P., Am. J. Physiol. Cell. Physiol., 288, C677-691, Epub 2004 Nov 2017 (2005).

37) Gustavsson J., Parpal S., Stralfors P., Mol. Med., 2, 367-372 (1996). 